$\begin{gathered}\text { Revista do Departamento de Geografia } \\ \text { Universidade de São Paulo } \\ \text { www.revistas.usp.br/rdg }\end{gathered}$
Volume Especial - XVII SBGFA / I CNGF (2017)
ISSN 2236-2878

\title{
Influência da Topografia e Uso da Terra na Variação dos Elementos Climáticos em Belo Horizonte, Ibirité, Sete Lagoas e Conceição do Mato Dentro - MG: O Segmento Temporal Entre 11 a 23/09/2016
}

\author{
Influence of topography and Land Use in Climatic Elements Variation in \\ Belo Horizonte, Ibirité, Sete Lagoas and Conceição do Mato Dentro-MG: \\ The Time Segment Between 11 and 23/09/2016
}

\author{
Marina Rozendo Silva \\ Universidade Federal de Minas Gerais \\ marinarozendo@yahoo.com.br \\ Carlos Henrique Jardim \\ Universidade Federal de Minas Gerais \\ dxhenrique@gmail.com
}

\begin{abstract}
Resumo: O objetivo deste artigo foi analisar as interações entre topografia e uso da terra nas variações de temperatura e umidade relativa do ar e sua contribuição na formação de subunidades climáticas. A área de estudo abrange os municípios de Belo Horizonte, Ibirité, Sete Lagoas e Conceição do Mato Dentro (Minas GeraisBrasil). Foram utilizados dados oriundos de séries temporais de estações meteorológicas e dados recolhidos em campo, cuja análise permitiu identificar possível distinção quanto à hierarquia na escala de influência dos fatores que organizam os climas nas localidades indicadas, variando desde a ação de sistemas atmosféricos em mesoescala até atributos pontuais de origem natural e antrópica em microescala.
\end{abstract}

Palavras-chave: Temperatura; Umidade; Vegetação; Relevo; Serra do Cipó.

\begin{abstract}
The purpose of this article was to analyze the interactions between topography and land use in the variations of temperature and relative humidity and its contribution in the formation of climatic subunits. The study area covers the municipalities of Belo Horizonte, Ibirité, Sete Lagoas and Conceição do Mato Dentro (Minas Gerais-Brazil). We used data from time series of meteorological stations and data collected in the field, whose analysis allowed to identify possible distinction as to the hierarchy in the scale of influence of the factors that organize the climates in these localities, ranging from the action of mesoscale atmospheric systems till specific attributes of natural and anthropogenic origin in microscale.
\end{abstract}

Keywords: Temperature; Humidity; Vegetation; Relief; Serra do Cipó. 


\section{INTRODUÇÃO}

A utilização da abordagem geossistêmica nos estudos do clima facilita a compreensão dos fenômenos atmosféricos, uma vez que se busca o entendimento do seu funcionamento através de complexas relações e interações com os diferentes sistemas (naturais e/ou antrópicos). No entanto, procurar compreender tais interações entre os fenômenos climáticos e as consequências desses eventos para a sociedade se mostra tarefa desafiadora, considerando a característica dinâmica e caótica do sistema climático e sua variação no espaço e no tempo.

As trocas de energia e matéria entre a atmosfera e a superfície terrestre ocorrem em diferentes escalas. Fatores presentes na superfície, como relevo e cobertura vegetal influenciam e controlam os elementos climáticos em escalas inferiores, enquanto a distribuição latitudinal da radiação solar, a curvatura da Terra e a inclinação do seu eixo controlam o clima em escalas superiores conforme Ribeiro (1993).

Segundo Ribeiro (1993), escalas inferiores são aquelas mais próximas dos indivíduos e da superfície terrestre, onde ocorrem as interações climáticas com a sociedade, sendo que a influência dos elementos presentes na superfície se torna mais acentuada nessas escalas, tendo limitada repercussão nas escalas superiores. Entretanto, os fenômenos climáticos ligados às escalas superiores interferem no comportamento da atmosfera em escalas inferiores.

Dessa forma, quanto menor a escala, maior o número de variáveis que interferem no comportamento dos elementos climáticos, tornando as análises em meso e microescalas mais complexas. A utilização dessas escalas nos estudos do clima permite verificar as interações e influências dos fatores climáticos na variação dos elementos atmosféricos que afetam diretamente a qualidade de vida humana, como a temperatura e umidade do ar.

Os estudos dos fenômenos relacionados com o comportamento da atmosfera são orientados no sentido da compreensão de sua extensão (espaço) e de sua duração (tempo). A definição da intensidade, frequência e, finalmente, de uma tipologia climática dependerá, basicamente, da adequação dessa abordagem espaço-temporal com o conjunto de técnicas analíticas empregadas no processo da pesquisa e comunicação dos seus resultados (RIBEIRO, p.288, 1993).

Sabe-se que a vegetação desempenha importante papel na variação dos elementos climáticos em escala local, elevando as taxas de umidade relativa e reduzindo consideravelmente os valores de temperatura do ar em relação ao seu entorno. Da mesma maneira, as características geomorfológicas de determinado lugar (relevo, altitude, declividade) também são capazes de influenciar de modo significativo na formação de subunidades climáticas.

No entanto, as alterações no uso da terra (atividade agropecuária, ocupações urbanas e o intenso processo de industrialização) modificam o balanço de energia, alterando o comportamento das variáveis climáticas locais. A ausência de áreas verdes, impermeabilização elevada do solo, presença maciça de concreto e asfalto favorecem o acúmulo de calor nessas áreas, alterando as taxas de umidade relativa do ar, circulação dos ventos e precipitação.

Considerando que o uso da terra e a topografia podem determinar o clima local, o trabalho pretende analisar e compreender a interação entre a temperatura e umidade relativa do ar com os fatores existentes nos municípios analisados e em pontos estratégicos do Parque Nacional da Serra do Cipó, como cobertura do solo, altitude, compartimentação geomorfológica e vegetação.

Estudos sobre a interação entre as modificações no uso do solo e os elementos climáticos se tornam de extrema importância considerando a significativa influência que os fatores climáticos presentes nos ambientes naturais e urbanos provocam nos elementos do clima, tornando possível a formação de enclaves climáticos em espaços relativamente próximos. Além do mais, a compreensão dos impactos causados por essas modificações pode contribuir na elaboração de melhores planejamentos urbanos, beneficiando a população residente dessas áreas. 


\section{CARACTERIZAÇÃO DA ÁREA DE ESTUDOS}

Belo Horizonte, considerado o município mais populoso de Minas Gerais com 2.513.451 habitantes, área aproximada de $331,41 \mathrm{~km}^{2}$, segundo dados do Instituto Brasileiro de Geografia e Estatística - IBGE, está localizada na região central de Minas Gerais $\left(19^{\circ} 46^{\prime} 35^{\prime}\right.$ ' S - 43 $51^{\circ} 47^{\prime}$ ' W), podendo-se distinguir duas unidades geomorfológicas: Depressão Sanfranciscana e Quadrilátero Ferrífero. De acordo com Assis (2010), a vegetação, assim como o clima, mostra grande relação com o relevo, que influenciam nos valores de temperatura do ar, além da direção e velocidade do vento, relacionados ao alinhamento topográfico da Serra do Curral (Figura 1).

O município de Ibirité, localizado cerca de $20 \mathrm{~km}$ da capital, integra a Região Metropolitana de Belo Horizonte (20 01 ' $15^{\prime}$ ' S - 40 03 ' $52^{\prime}$ ' W), ocupando área de aproximadamente $73 \mathrm{~km}^{2}$ e população estimada de 175.721 habitantes. A porção sul do município apresenta relevo com declividade e desníveis topográficos elevados.



Figura 1: Localização da área de estudo no estado de Minas Gerais. Os valores de latitude e longitude das cidades são aproximados e o valor de altitude corresponde ao das estações meteorológicas do INMET e mensurada em campo no Pq. Nac. Serra do Cipó. Fonte: Google Earth, fev. 2017.

O município de Sete Lagoas faz parte do Colar Metropolitano de Belo Horizonte, estando localizada


IBGE, a população estimada no município é de 234.221 habitantes, com área aproximada de $536 \mathrm{~km}^{2}$. De acordo com Leão (2008), a Serra de Santa Helena divide a rede hidrográfica de Sete Lagoas em duas bacias, a do Rio Paraopeba e Rio das Velhas, e a vegetação predominante no município é o cerrado, substituído em grande parte por pastagens e culturas.

Segundo dados da Prefeitura Municipal (2017), Conceição do Mato Dentro encontra-se localizada na região central do estado de Minas Gerais, a cerca de $167 \mathrm{~km}$ de Belo Horizonte e população estimada em 18.160 hab. $\left(19^{\circ} 02^{\prime} 13^{\prime}\right.$ 'S $\left.-43^{\circ} 25^{\prime} 30^{\prime \prime} \mathrm{W}\right)$. O município está inserido da vertente oriental da Serra do Cipó, na Cadeia do Espinhaço, apresentando relevo montanhoso. Sua área territorial ocupa 1.726,831 km². 
Em relação ao clima, as áreas estudadas estão inseridas numa região de influência entre os sistemas atmosféricos tropicais e extratropicais, caracterizados por períodos alternadamente secos e úmidos (ASSIS, 2010). Dessa forma, a região está em constante domínio de sistemas frontais e linhas de instabilidade, que se constituem num dos principais fatores genéticos das chuvas nesses locais e definem os valores de temperatura observados durante o ano. Outros fatores como disposição do relevo e continentalidade também influenciam na distribuição e variação dos elementos climáticos (NUNES et al., 2009).

O Parque Nacional da Serra do Cipó, criado em setembro de 1984, situado na área central do estado de Minas Gerais, está localizado a cerca de $100 \mathrm{~km}$ de Belo Horizonte com uma área total de 33.800 hectares. Considerada o divisor de água das bacias hidrográficas do Rio São Francisco e Rio Doce, a Serra do Cipó está inserida na porção sul da Cadeia do Espinhaço, com predomínio de vegetação de cerrado e presença campos rupestres, mata atlântica, além de casos de endemismo florístico (VIEIRA et al, 2005). As altitudes variam entre 700 e 1.670 metros.

\section{MATERIAIS E MÉTODOS}

Foram utilizados dados de temperatura do ar e umidade relativa obtidos das estações meteorológicas de observação em superfície, mantidas pelo Instituto Nacional de Meteorologia (INMET), num período que abrangeu os dias 11 a 23 de setembro de 2013, dos municípios de Belo Horizonte, Ibirité, Sete Lagoas e Conceição do Mato Dentro. Para a escolha dos municípios considerou-se primeiramente a proximidade com Belo Horizonte, os diferentes graus de transformação das características de uso e ocupação da terra e a presença de estações meteorológicas mantidas pelo INMET. Os dados de temperatura e umidade relativa foram recolhidos do Banco de Dados Meteorológicos para Ensino e Pesquisa do INMET (BDMEP).

Com a finalidade de comparar os dados das estações inseridas nos municípios, utilizou-se os dados dos abrigos meteorológicos móveis instalados dentro do Parque Nacional da Serra do Cipó - MG, a fim de verificar o grau de influência de fatores como vegetação, cobertura do solo e altitude na variação dos elementos climáticos. Os dados recolhidos dos abrigos meteorológicos móveis foram os de temperatura do ar e umidade relativa de três diferentes postos, sendo eles o posto Mata Ciliar, posto Cerrado e posto Capão. Os abrigos foram instalados considerando fatores como a vegetação, incidência da radiação, relevo, altitude, visando compreender a relação e influência desses fatores na variação dos elementos do clima. Os dados foram coletados através de registradores automáticos tipo data logger, instrumento responsável por medir e registrar as variáveis climáticas (temperatura, umidade relativa do ar e temperatura do ponto de orvalho) em intervalos de uma hora, aferidos com os dados da estação meteorológica do INMET Belo HorizontePampulha.

Com o objetivo de analisar e identificar a influência dos fatores climáticos na variação dos elementos do clima foram elaborados gráficos das médias de temperatura e umidade relativa do ar das sete localidades selecionadas. Para isso, utilizou-se o programa Microsoft Excel para a tabulação dos dados e construção dos gráficos.

As cartas sinóticas retiradas do Centro de Hidrografia da Marinha e imagens de satélite da Divisão Satélites e Sistemas Ambientais do CPTEC/INPE foram analisadas a fim de identificar os sistemas atmosféricos atuantes nos dias analisados e estabelecer as relações e influências dos tipos de tempo nos microclimas identificados na área de estudo.

Deve-se ressaltar que nesta pesquisa foram utilizados dados dos horários sinóticos em cada uma das localidades estudadas, em razão da ausência de estações meteorológicas de superfície automáticas em alguns dos municípios selecionados. Os horários sinóticos privilegiam os horários mais quentes do período diurno que, por sua vez, tende a interferir no valor das médias diárias.

\section{RESULTADOS E DISCUSSÕES}

Os valores de temperatura das sete localidades seguem um mesmo padrão de comportamento durante o período analisado, em consequência dos sistemas atmosféricos atuantes na região ao longo dos dias de coleta dos dados. O aumento da temperatura em sentido ao dia 15/09, assim como nos dias 18/09 e 19/09 é resultante do aquecimento pré-frontal. Com o avanço do sistema frontal, o ar adjacente torna-se mais quente, causando diminuição da pressão e a drenagem de calor para essa área, provocando o aumento das temperaturas. 
Entre os dias 16/09 e 17/09 e 20/09 a 21/09 ocorre a atuação da Frente Polar Atlântica, ocasionando queda das temperaturas e aumento da nebulosidade e da umidade relativa do ar. De acordo com Mendonça e Danni-Oliveira (2007, p.103) "a passagem [...] de frente fria sobre uma determinada região é acompanhada por instabilidade atmosférica, alternância de tipos de tempo e, genericamente, ocorrência de precipitações".

Em condições de nebulosidade elevada, parte da entrada de radiação direta é bloqueada pelas nuvens, favorecendo a radiação difusa. Dessa forma, a quantidade de radiação de ondas curtas que atinge a superfície é menor, refletindo em menor quantidade de calor disponível, proporcionando baixos valores de amplitude térmica (LOPES E JARDIM, 2012) e diminuindo consideravelmente as diferenças entre as localidades analisadas.

Por outro lado, existem diferenças significativas e particulares no comportamento de tais elementos que só podem ser compreendidas quando se analisa o ambiente em que as estações e os abrigos meteorológicos foram instalados, considerando aspectos como orientação com as vertentes, cobertura do solo, altitude e vegetação.

Em Conceição do Mato Dentro observou-se a maior amplitude térmica dentre os sete pontos analisados $\left(26,2^{\circ} \mathrm{C}\right)$, registrando a menor temperatura mínima absoluta $\left(10,5^{\circ} \mathrm{C}\right)$ assim como a maior temperatura absoluta $\left(36,7^{\circ} \mathrm{C}\right)$. Esse valor pode ser explicado, primeiramente, em função da altitude de 652 $\mathrm{m}$ (menor valor em relação dos demais postos). Secundariamente em razão da vegetação rasteira e da baixa cobertura arbórea presente no local de instalação da estação meteorológica (próximo a uma pista de pouso), onde a troca de calor entre a superfície e atmosfera se torna mais significativa. $\mathrm{O}$ dossel aberto favorece a entrada de radiação direta, disponibilizando maior quantidade de calor para aquecer o ar. Da mesma forma, com o pôr do Sol, a falta de cobertura florestal favorece a perda maior de radiação, provocando queda nas temperaturas.

Ibirité também registrou amplitude térmica baixa $\left(19,4^{\circ} \mathrm{C}\right)$ e o menor valor de temperatura máxima absoluta $\left(31,7^{\circ} \mathrm{C}\right)$, provavelmente pelo fato de que a estação meteorológica do município se encontrar em altitude muito elevada (1.199 metros), principalmente se comparada aos demais postos. A altitude contribui com a diminuição da temperatura, uma vez que há menor disponibilidade de partículas de gases para reter e armazenar o calor.

No posto Mata Ciliar, o baixo valor da amplitude térmica $\left(18,4^{\circ} \mathrm{C}\right)$ pode ser explicado pelo elevado dossel arbóreo presente no local de instalação do abrigo. A cobertura vegetal intercepta parte da radiação solar que incide sobre a superfície, diminuindo a quantidade de calor disponível para aquecer o ar adjacente. A presença de vegetação e a proximidade de corpos d'água também contribuem para a manutenção do calor durante o dia, uma vez que o vapor d'água tem a capacidade de reter calor. Nessas áreas, parte da energia disponível (calor) é utilizada no processo de evaporação da água dos rios e do solo e no processo de transpiração das plantas, retirando calor sensível do ar circundante transformando-o em calor latente, reduzindo assim as temperaturas.

Ainda que a Mata Ciliar tenha registrado o menor valor de amplitude térmica dentre todos os postos, os valores de temperaturas mínima e máxima absolutas $\left(15,8^{\circ} \mathrm{C}\right.$ e $34,2^{\circ} \mathrm{C}$, respectivamente) desse posto se mostraram relativamente elevados e apresenta uma das maiores médias (Tabela 1). Apesar de apresentar um dossel arbóreo fechado, a existência de umidade nas folhas das árvores presentes nesse posto de coleta contribui para o aumento da absorção de radiação pela superfície foliar durante o dia (LEITÃO et al., 2002). Outro fator que pode explicar tais valores é a densidade da vegetação que implica na obstrução do vento, impedindo a dissipação do calor, contribuindo para o registro de temperaturas mais altas.

Considerando que em grande parte dos dias analisados a região encontrava-se sob domínio de sistemas de alta de pressão (Sistema Tropical do Atlântico e Sistema Polar do Atlântico), espera-se que os valores de amplitude térmica sejam mais altos. A atuação dessas massas de alta pressão favorece a ausência de nuvens que, por sua vez, proporciona maior incidência de radiação solar durante o dia e consequentemente maior perda energética durante a noite, considerando que as nuvens atuam como barreira à radiação solar em razão da elevada taxa de albedo e dificultam a saída da radiação em ondas longas (radiação terrestre), contribuindo para o processo de contrarradiação. 
Tabela 1: Dados de temperatura e umidade relativa dos postos analisados.

\begin{tabular}{|l|c|c|c|}
\hline & Altitude (m) & Temperatura Média $\left({ }^{\circ} \mathbf{C}\right)$ & Umidade Relativa \\
\hline Belo Horizonte & 915 & 25,1 & 47 \\
\hline Ibirité & 1199 & 21,8 & 54 \\
\hline Sete Lagoas & 719 & 24,5 & 54 \\
\hline C. do Mato Dentro & 652 & 24,7 & 59 \\
\hline Mata Ciliar & 801 & 25,4 & 45 \\
\hline Cerrado & 802 & 26,2 & 43 \\
\hline Capão & 986 & 25,3 & 43 \\
\hline
\end{tabular}

Comparando as médias diárias das temperaturas nos postos analisados (Figura 2), percebe-se que o município de Ibirité apresenta os valores mais baixos em relação aos demais $\left(21,8^{\circ} \mathrm{C}\right)$. Como mostrado na tabela, essa estação meteorológica está instalada em cota de altitude mais elevada (1.199 metros), portanto os valores de temperatura tendem a ser mais baixos em razão da diminuição da pressão atmosférica, propiciando o aumento do volume do ar e redução de sua densidade, que acarreta em menor quantidade de calor contido, e consequente diminuição da temperatura, cujo valor teórico corresponde à redução de $0,65^{\circ} \mathrm{C} / 100 \mathrm{~m}$. De acordo com Torres e Machado (2008) o fator altimétrico contribui para a diminuição dos valores térmicos uma vez que a atmosfera é aquecida de baixo para cima, através da irradiação terrestre. Sendo assim quanto mais distante da superfície menor é a temperatura do ar.

Deve-se considerar também que a serra provoca o levantamento orográfico do ar, que por sua vez se expande e se resfria (resfriamento adiabático). Além disso, durante o dia, as vertentes voltadas para o Sol se aquecem mais rapidamente em relação às áreas mais baixas do relevo, causando o direcionamento do vento para as partes mais altas (ventos anabáticos). Durante a noite, o ar sobrejacente às vertentes se esfria mais rapidamente em relação às áreas deprimidas, ocasionando o escoamento para áreas mais baixas (ventos catabáticos). Possivelmente a estação meteorológica instalada em Ibirité capta essas circulações que interferem nos valores de temperatura local.

A estação meteorológica de Ibirité se encontra no limite sul do município, no interior do Parque Estadual Serra do Rola Moça, em área periurbana, próximo a superfícies florestais de grande extensão. Como mencionado anteriormente, além de atuar como barreira à radiação solar direta, o que resulta em menor disponibilidade de calor, os processos de transpiração das plantas contribuem para a retirada de calor sensível disponível para aquecer o ar, favorecendo temperaturas mais baixas.

\section{Temperatura média diária (11/09 a 23/09)}

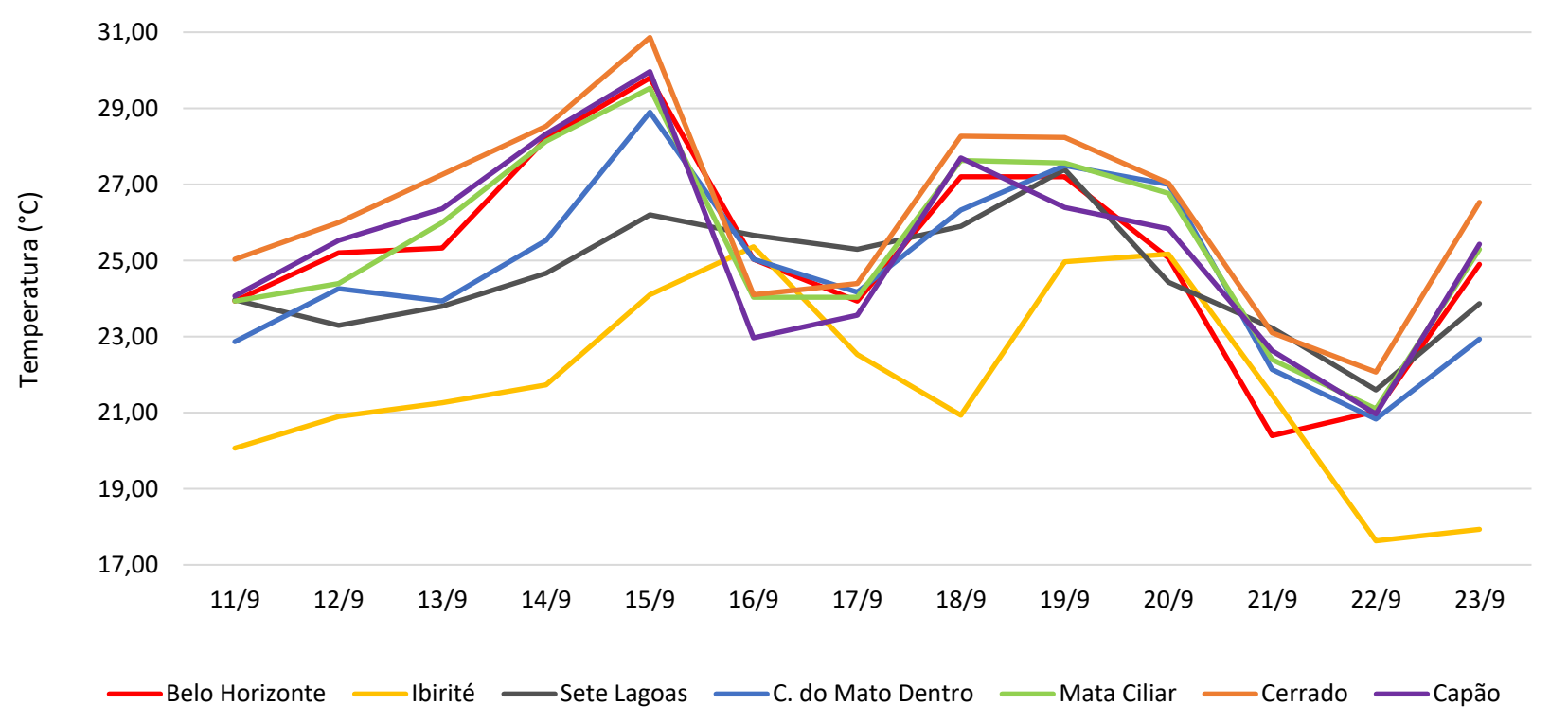

Figura 2: Gráfico da temperatura média diária dos postos analisados. 
Em relação à temperatura média mais alta, destaca-se o posto Cerrado e Capão $\left(26,2^{\circ} \mathrm{C}\right.$ e $\left.25,3^{\circ} \mathrm{C}\right) . \mathrm{O}$ dossel aberto encontrado no local de instalação do abrigo favorece a incidência de radiação solar direta na superfície. Durante o dia, o solo desempenha papel de reservatório de calor, aquecendo o ar no entorno e contribuindo para a elevação das temperaturas. Ainda que baixa, o posto cerrado apresenta vegetação de pequeno porte, isto é, dossel permeável.

Em áreas marcadas pela ausência de vegetação, os processos de troca de energia entre o solo e o ar são mais diretos (MENDONÇA E DANNI-OLIVEIRA, 2007), isto é, a quantidade de radiação solar que atinge a superfície é consideravelmente maior, enquanto nas áreas com dossel arbóreo fechado, há pouca ou nenhuma incidência direta de radiação solar na superfície.

Já nas áreas de cerrado esses processos de troca de calor revelam-se mais complexos. Durante o período de seca, em razão da baixa disponibilidade de água, algumas árvores perdem suas folhas, favorecendo a entrada de radiação direta na superfície. No entanto, os galhos e troncos tortuosos que integram a mata atuam como barreira à saída dessa energia, criando um jogo de reflexões, aprisionando o calor no interior da mata. Da mesma forma que a estrutura de galhos permite a entrada de radiação direta, o baixo adensamento da vegetação facilita a entrada do ar circundante aquecido, contribuindo com aumento das temperaturas através da advecção do ar quente. Conclusões semelhantes foram obtidas por Jardim (2005) em experimentos de microclima no interior de Goiás.

Além do mais, a vegetação de pequeno porte (vegetação rasteira, baixa cobertura arbórea) e a distância de corpos d'água contribui para os baixos valores de umidade relativa, que por sua vez auxiliam na manutenção das altas temperaturas, dado que a água atua como controlador térmico devido ao seu elevado calor específico, enquanto a vegetação transforma calor sensível em calor latente no processo de evapotranspiração.

No que diz respeito aos valores de umidade relativa do ar (Figura 3), o município de Conceição do Mato Dentro se destaca com taxa de umidade significativamente maior que as demais localidades. Esse valor pode ser explicado pelo fato de que o município se encontrar a leste da cadeia do Espinhaço, cuja posição geográfica de barlavento, favorece a influência da umidade advectada do oceano Atlântico pelas massas de ar vindas de leste, caso do ASAS que atua durante o ano inteiro, com ventos de leste.

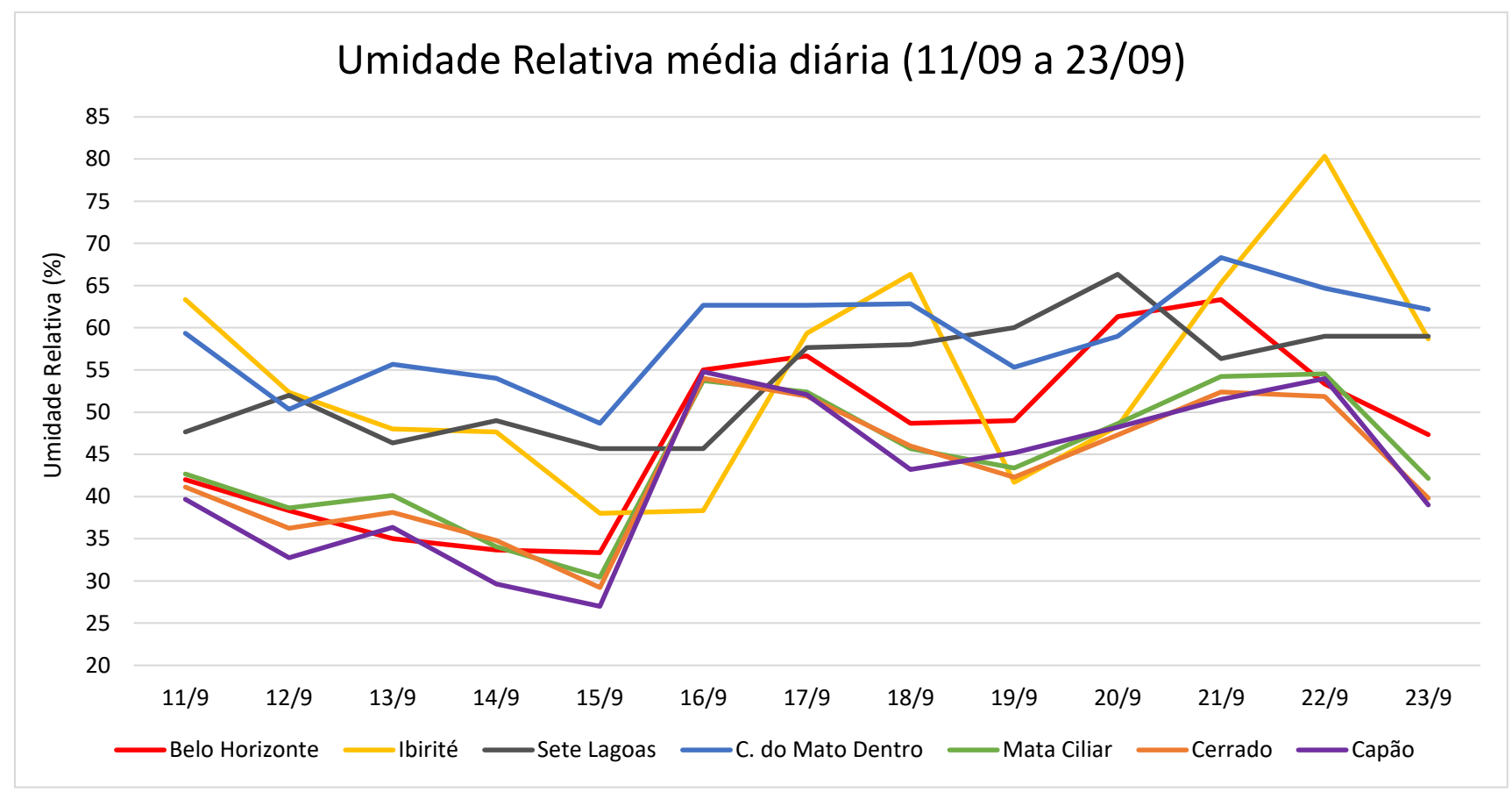

Figura 1: Gráfico da umidade relativa média dos postos analisados.

Segundo Ribeiro et al., (2009) a Cadeia do Espinhaço atua como barreira para o sistema tropical do Atlântico (STA), resultando numa linha de disposição de nebulosidade na porção leste da Cadeia. A intensidade do sistema tropical controla a incidência de nebulosidade, e ainda segundo os autores: 
A umidade permanece estacionária com condensação de nebulosidade, mesmo nos períodos secos, com registro de chuviscos, evidenciando um caráter totalmente orográfico do clima na região, em intenso contraste com a região melhor estudada, que fica na sombra das chuvas, com menor precipitação que a capital Belo Horizonte. (RIBEIRO et al., p.39, 2009).

O posto Capão apresenta os índices mais baixos de umidade relativa, possivelmente devido à presença de vegetação mais esparsa e menos expressiva, além de distante de corpos d'água. Deve-se considerar também que a altitude influenciou nos valores encontrados, considerando que o ar menos denso tem menor capacidade de reter vapor d'água.

No gráfico (Figura 4) comparando os valores de temperatura nos três horários sinóticos analisados $(09,15$ e 21 h) fica nítido certo padrão de comportamento da temperatura nas localidades estudadas. Durante o período da manhã (09 h), os postos do Parque Nacional da Serra do Cipó apresentam os valores mais elevados em comparação aos dados obtidos das estações instaladas nos quatro municípios analisados. Em relação ao horário das $21 \mathrm{~h}$, a situação se inverte, os municípios apresentam valor de temperatura mais elevado que os postos do Parque. No horário referente às 15 h, com exceção de Ibirité, as temperaturas nas sete localidades pouco se diferenciam.

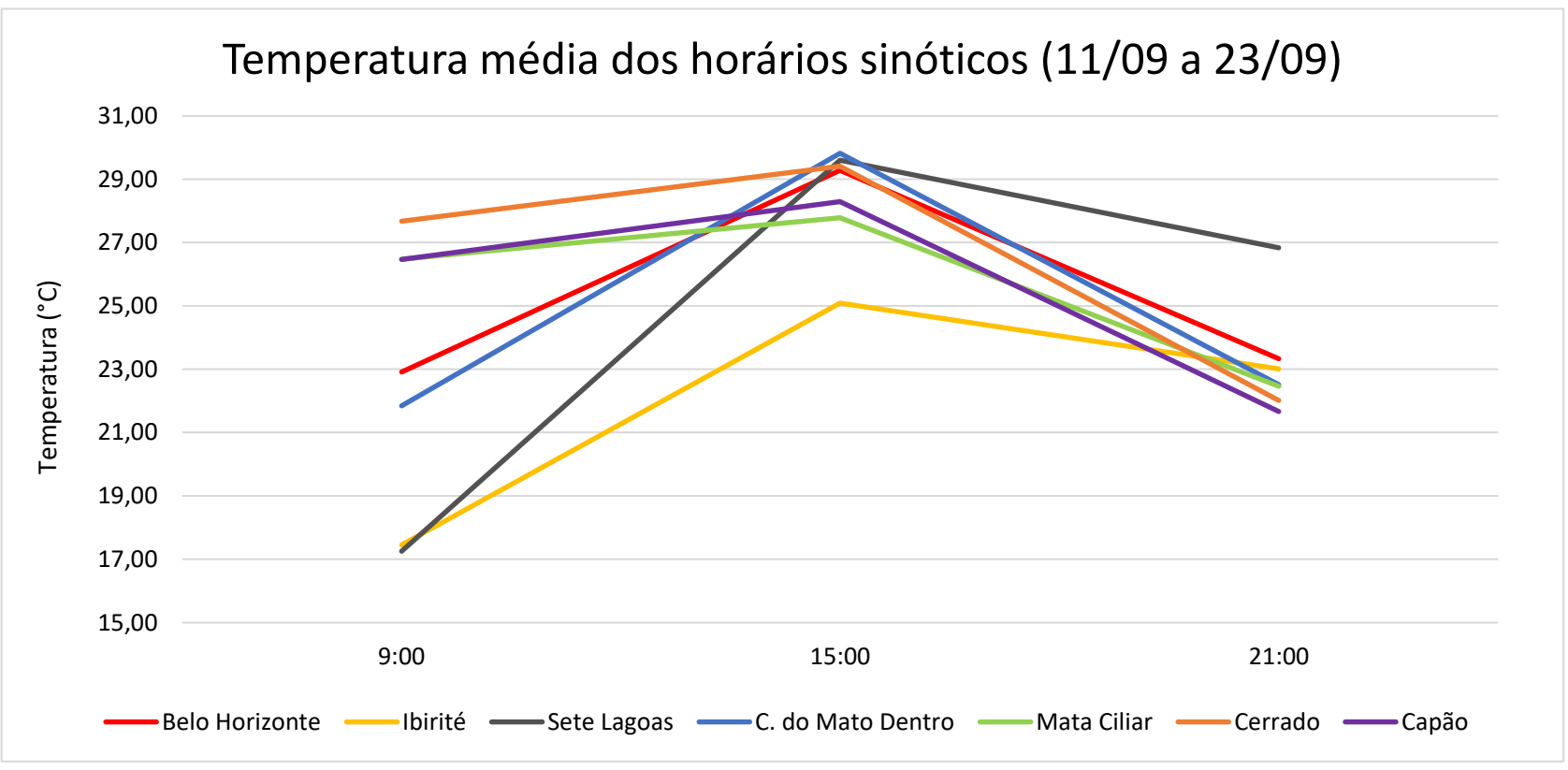

Figura 2: Gráfico comparativo entre os municípios analisados da temperatura média diária.

Em condições de tempo estável (baixa nebulosidade e ventos fracos), especialmente nas áreas mais baixas do relevo, a superfície perde calor de forma mais rápida para a camada de ar sobrejacente, que por sua vez transmite o calor para a camada acima, tornando-se mais frio que o ar acima, gerando o fenômeno de inversão térmica (MENDONÇA E DANNI-OLIVIEIRA, 2007). Considerando que os municípios de Belo Horizonte, Sete Lagoas e Conceição do Mato Dentro encontram-se em áreas deprimidas, presume-se que as temperaturas mais baixas no período da manhã estejam relacionadas a esse fenômeno.

Já nas áreas do Parque Nacional da Serra do Cipó, apesar dos abrigos instalados em áreas mais baixas do relevo, a cobertura do solo foi o fator predominante. Ao amanhecer, nos horários que registram menor valor de temperatura e em ambientes úmidos, o vapor d'água é condensado através do contato com uma superfície mais fria, ocasionando a formação de orvalho. Durante esse processo de condensação, ocorre a liberação de calor, aumentando a temperatura do ar. 
Em relação ao horário das $21 \mathrm{~h}$, de maneira geral, ao longo da noite, a superfície aquecida durante o dia cede calor para a atmosfera até que o solo fique mais frio que o ar e inverta a situação, drenando calor do ar. Esse processo estabelece o balanço negativo de radiação, quando as temperaturas tendem a cair em razão da perda da energia armazenada (LOPES E JARDIM, 2012). No entanto a presença de elementos característicos das cidades favorece o acúmulo e a produção de calor, como o asfalto e o concreto. Em função do seu calor específico e da elevada condutividade térmica, esses materiais absorvem a energia solar de maneira diferenciada.

A capacidade de estocagem de calor nas cidades é consideravelmente maior em relação às áreas naturais devido à presença de instalações industriais, circulação de veículos mais intensa, poucas áreas verdes etc., resultando no aumento de temperatura. Sendo assim, mesmo após o pôr-do-sol, a perda de calor nessas áreas ocorre de forma mais lenta, uma vez que parte da energia recebida é armazenada pelas estruturas presentes nas cidades, que demoram mais tempo para dissipar o calor.

Nas áreas naturais, a vegetação, por ser mal condutora de calor, dissipa a energia armazenada ao longo do dia logo após o anoitecer, contribuindo para que as temperaturas nesses ambientes sejam menores em relação às áreas urbanas.

\section{CONCLUSÕES}

Pode-se afirmar que em razão dos ambientes montanhosos do Parque Nacional da Serra do Cipó encontram-se diferenças climáticas significativas em espaços relativamente próximos, criando microclimas em consequência de condições paisagísticas singulares. A presença (ou ausência) de vegetação interfere consideravelmente na quantidade de energia existente no ambiente que, por sua vez, influencia no total de calor disponível, regulando os valores de temperatura e umidade do ar. Da mesma forma, a topografia também se revelou um importante fator, e por vezes determinante, na variação dos elementos climáticos.

Verificou-se a partir dos dados das estações meteorológicas dos quatro municípios a participação dos fatores antrópicos, ainda que em diferentes graus conforme o nível de alteração do uso da terra de cada município, atuando simultaneamente com os fatores naturais (vegetação e relevo) no comportamento das variáveis climáticas.

Deve-se chamar atenção, também, para os eventos de ordem escalar superior. Aspectos físicos regionais da área de estudo bem como os fenômenos climáticos de mesoescala que atuam na região influenciam nos valores encontrados em conjunto com os aspectos locais e em microescala da Serra do Cipó sendo capazes, em determinadas situações, de anular os efeitos dos fatores naturais e antrópicos em escalas inferiores.

\section{BIBLIOGRAFIA}

ASSIS, W. L. O sistema clima urbano do município de Belo Horizonte na perspectiva têmporo-espacial. Tese (Doutorado em Geografia). Universidade Federal de Minas Gerais - Instituto de Geociências, Belo Horizonte, 2010. 299p.

CENTRO de Hidrografia da Marinha. Serviço Meteorológico Marinho. Disponível em: <https://www.mar.mil.br/dhn/chm/meteo/prev/cartas/cartas.htm>. Acesso em 12 de fevereiro de 2017.

DSA - Divisão Satélites e Sistemas Ambientais. INPE - Instituto Nacional de Pesquisas Espaciais. Disponível em: <http://satelite.cptec.inpe.br/home/index.jsp>. Acesso em 12 de fevereiro de 2017.

INMET, Instituto Nacional de Meteorologia. BDMEP - Banco de Dados Meteorológicos para Ensino e Pesquisa. Disponível em: 〈http://www.inmet.gov.br/portal/index.php?r=bdmep/bdmep>. Acesso em 12 de fevereiro de 2017.

JARDIM, C. H. Microclimas em Morrinhos, Serra de Caldas e Paraúna, no sudeste de Goiás. In: XI SIMPÓSIO BRASILEIRO DE GEOGRAFIA FÍSICA APLICADA, 2005, São Paulo. Anais... São Paulo: Departamento de Geografia/FFLCH/USP, 2005. 1 CD-Rom.

LEÃO, M. S. Diagnóstico climático e estudo das variações termo-higrométricas do município de Sete Lagoas - MG. Dissertação (Mestrado em Geografia), Programa de Pós-Graduação em Geografia, Universidade Federal de Minas Gerais, Minas Gerais, 150 p. 2008. 
LEITÃO, M. M.V.B.R, DOS SANTOS, J. M. E DE OLIVEIRA G. M. Estimativas do albedo em três ecossistemas da floresta amazônica. Rev. bras. eng. agríc. ambient., vol.6, no.2, p.256-26. 2002.

LOPES, L. C. S.; JARDIM, C. H. Variações de temperatura e umidade relativa do ar em área urbana e rural durante o segmento temporal de inverno de $2011 \mathrm{em} \mathrm{Contagem} \mathrm{e} \mathrm{Betim} \mathrm{(MG).} \mathrm{ACTA} \mathrm{Geográfica,} \mathrm{Boa}$ Vista, Ed. Esp. Climatologia Geográfica, p. 205-221. 2012.

MENDONÇA, F.; DANNI-OLIVEIRA, I. M. Climatologia: noções básicas e climas do Brasil. São Paulo: oficina de texto, 206p. 2007.

NUNES, L. H; VICENTE, A. K; CANDIDO, D. H. Clima da região sudeste do Brasil. In: CAVALCANTI, I.F.A.; FERREIRA, N.J.; SILVA, M.G.A.J.; SILVA DIAS, M.A.F. (Orgs.) Tempo e clima do Brasil. 1.ed. São Paulo: Oficina de Textos, 464p. 2009.

Prefeitura Municipal de Conceição do Mato Dentro. Disponível em: <http://cmd.mg.gov.br/aspectosgerais/aspectos-fisicos-e-geograficos>. Acesso em 12 de fevereiro de 2017.

RIBEIRO, A. G. As escalas do clima. Boletim Geografia Teorética, Rio Claro, v. 23, p. 288-294, 1993.

RIBEIRO, K.T.; NASCIMENTO, J.S.; MADEIRA, J.A. \& RIBEIRO, L.C. Aferição dos limites da Mata Atlântica na Serra do Cipó, MG, Brasil, visando maior compreensão e proteção de um mosaico vegetacional fortemente ameaçado. Natureza \& Conservação, 7(1): p. 30-48. 2009.

TORRES, F. T. P.; MACHADO, P. J. O.. Introdução à Climatologia . Ubá: Geographica, 214p. 2008.

VIEIRA, F.; SANTOS, G. B.; ALVES, C. B. M. A ictiofauna do Parque Nacional da Serra do Cipó e áreas adjacentes. Lundiana (UFMG), Belo Horizonte, v. 6, p. 77-87, 2005. 